\title{
MEDICAL STUDENTS' FEEDBACK ON PARADIGM SHIFT TO ONLINE TEACHING DURING COVID-19 LOCKDOWN
}

Dr. R. Ravi Sunder

\section{Dr. I. Jyothi Padmaja}

Dr. Neelima. P*
Professor, department of Physiology, GITAM Institute of Medical Sciences \& Research, GITAM UNIVERSITY, Rushikonda, Visakhapatnam, Andhra Pradesh, India-530045.

Principal, GITAM Institute of Medical Sciences \& Research, GITAM University, Rushikonda, Visakhapatnam, Andhra Pradesh, India-530045.

Professor, department of Anatomy, GITAM Institute of Medical Sciences \& Research, GITAM University, Rushikonda, Visakhapatnam, Andhra Pradesh, India-530045.

ABSTRACT The temporary shutdown of educational institutes due to COVID -19 lockdown has led to the transformation of face to face classroom teaching to virtual online learning. The present study is aimed to evaluate the challenges faced by the first year medical students. After taking informed consent, a self administered questionnaire with 15 questions was given in google form. 148 students (62 boys, 86 girls) between the age group 17-23 years participated in the study. The answers were represented graphically. The results were analysed and compared with other studies. $84.3 \%$ students opined that they learnt the concepts better by hands on exposure than online teaching. Only $10.7 \%$ students replied that online tasks improve their self-discipline. $78.6 \%$ answered that the teacher was available when they needed help. $46 \%$ stated that the teacher's feedback helped them in online learning. $40 \%$ accepted the need for online teaching to be combined with the traditional teaching, post COVID in their curriculum. The results were similar to the other studies when compared. Most of them experienced the technical glitches, connectivity issues, suspended video streaming etc. that interrupted their online learning. The present study concludes that the medical students prefer face to face traditional classroom teaching than online teaching amidst advanced technology.

KEYWORDS : Medical students, online learning, feedback, COVID-19.

INTRODUCTION

The pandemic COVID-19 has led to the implementation of lockdown for the first time in India, reflecting both positive and negative effects. The health of the people was prioritized though the Indian economy, business, employment was hit worst. On the other hand, lockdown phenomenon brought incredible changes in the environment, atmosphere and lifestyles. Toughest challenge has been faced by the education system.

As the saying goes- "Necessity is the mother of invention", the concept of online teaching and digital technology came to rescue the education system during the pandemic 2020. Vitoria etal ${ }^{(1)}$ described that the magnanimity of information technology's influence cannot by refuted. Study by Anca etal ${ }^{(2)}$ determines the efficacy of implementation of e-learning. Psychomotor and affective skills form the major domain in the art of learning Medicine. The virtual online learning can meet the cognitive domain but for the other domains of learning. Studies by Maheshwari etal ${ }^{(3)}$ and Frehywot etal ${ }^{(4)}$ illustrated the effective e- learning in medical education. Singh etal ${ }^{(5)}$ concluded that majority of students were satisfied with the digital learning in Anatomy lectures. The present study was conducted to analyze the students' responses towards the paradigm shift to online teaching.

\section{MATERIALS \& METHODS}

A self-administered questionnaire with 15 questions was given to the students by google form after taking an informed consent. 148 students from first phase of MBBS participated in the study. 86 were girls and 62 were boys with age ranging from 17-23 years. The questions from 1-13 had three optionsyes, somewhat and no. The results were analysed and represented graphically. The feedback was compared with other studies.

\section{RESULTS}

The following results were obtained from the study.

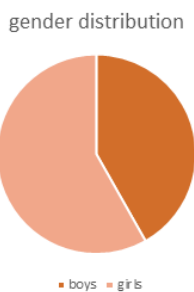

Graphl: Gender Distribution In The Study

Table 1: Questionnaire Format

\section{S No. Question}

\begin{tabular}{l|l|l}
\hline l. & Is the time sufficient for you in understanding the
\end{tabular} subject?

2. Are you satisfied with the online teaching provided to you?

3. Do you understand the concepts in online teaching as good as when taught by hands on exposure?

4. Did you ever skip a class just because you don' understand and grasp the concepts online?

5. Online tasks improve your self-discipline.

6. Is the purpose of taking exams online making you to get practice and get rid of exam apprehension?

7. Do you feel assignments given for you served you better?

8. $\quad$ Do you think there is a need for a crash course revision before exams?

9. $\quad$ Are your teachers providing you several different ways to demonstrate and easily understand the content of online classes?

10. Are your teachers available to you when you need help?

11. Does your teacher's feedback support you in your online learning?

12. Do you feel that you are physically isolated from your classmates? 
13. Do you feel the need for online teaching to be combined with the traditional teaching, post COVID in your curriculum?

14. Do you experience any technical glitches in online teaching? Mark the appropriate options.

15. How would you communicate with your teachers in solving the concepts?

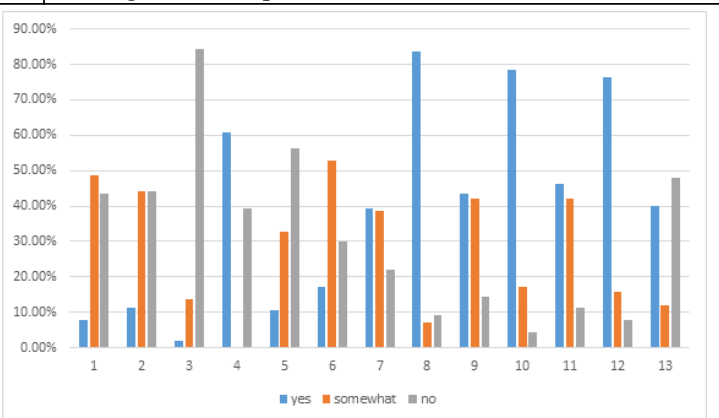

Graph 2: Responses For The Questions 1-13

Do you experience any technical glitches in online teaching? Mark the appropriate options.

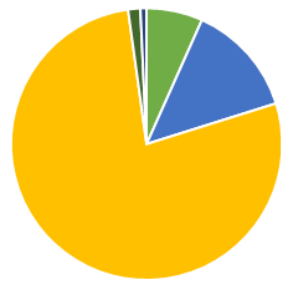

" audibility " video streaming " connectivity issues , all of the above " no issues

Graph 3: Responses For The Question 14

How would you communicate with your teachers in solving the concepts?

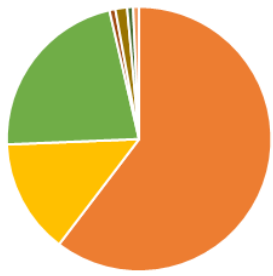

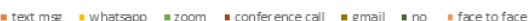

Graph 4: Responses For Question 15

The feedback from the present study was compared with the study made by Thomas etal ${ }^{(6)}$ and Abbasi etal ${ }^{(7)}$. Medical students from the present study opined that the face to face learning was far better preferred when compared to online learning during the covid-19 lockdown which is similar conclusion from the other studies.

\section{DISCUSSION}

The unanticipated catastrophe of COVID-19 has completely changed the traditional teaching methodologies to virtual online learning. Both the students as well as faculty were forced to face the consequences of the new teaching learning method. Online teaching has been a component of the blended teaching since a long time. Studies by Qureshi etal ${ }^{(8)}$ and Bali ${ }^{(9)}$ show the preferences towards face to face learning over online learning. Surprisingly there are few studies ${ }^{(5,10)}$ which explain the students' preference for online learning. However, the preferences vary with the course syllabus, tenure, time schedules, learning management system used, connectivity etc. The present study depicts $84.3 \%$ students preferred traditional face to face teaching when compared to online learning. $83.6 \%$ opined the need for a crash course before their exams. $78.6 \%$ replied that the teacher was available when they needed help and $58.6 \%$ communicated with their teachers using text message. As many as $76.4 \%$ students felt that they were physically isolated from their classmates. The results were compared with other studies reported by Abbasi etal and Thomas etal. The results of the present study were similar to their findings. This illustrates the need for traditional teaching amidst advanced technology where the student understands the subject thoroughly.

\section{CONCLUSION}

The medical students' feedback on the paradigm shift to online learning depicts the preferences towards face to face traditional classroom teaching which correlated with other studies. Network connectivity issues, video streaming, technical glitches were experienced by most of the students which interrupted their learning. They chose to learn concepts by hands on learning when compared to online teaching.

\section{REFERENCES}

1. Vitoria L, Mislinawati M, Nurmasyitah N. Students'perceptions on the implementation of e-learning:Helpful or unhelpful? J Physics. 2018:1088.

2. Anca P, Cosmina M. Students'Perception on Using eLearning Technologies. Procedia Soc Behav Sci. 2015;180:1514-1519. doi:10.1016/ j.sbspro. 2015. 02.300 .

3. Maheshwari S, Zheleva B, Rajasekhar V, Batra B. e-Teaching in pediatric cardiology: A paradigm shift.Ann Pediatr Cardiol. 2015 Jan-Apr; 8(1):10-3.

4. Frehywot S, Vovides Y, Talib Z, Mikhail N, Ross H, Wohltjen H, Bedada S, Korhumel K, Koumare AK, Scott J. E-learning in medical education in resource constrained low- and middle-income countries.Hum Resour Health. $2013 \mathrm{Feb}$ $4 ; 11(): 4$.

5. Singh A, Min AK. Digital lectures for learning gross anatomy: a study of their efficacy.Korean J Med Educ. 2017 Mar; 29(1):27-32.

6. Thomas, A., Shenoy, M. T., K. T., S. Suresh Kumar, S. Sidheeque, A., C. Khovidh, Pillai, J. P., Pillai, P. M., CH, S. S., Mathew, A., Zakkir, T., Dileep, S. Mekha, V., Raju, S., Junaid K., M., \& P., S. (2020). Survey Among Medical Students During COVID-19 Lockdown: The Online Class Dilemma. International Journal of Medical Students. https://doi.org/10.5195/ijms.2020.571

7. Abbasi, S., Ayoob, T., Malik, A., \& Memon, S. (2020). Perceptions of students regarding E-learning during Covid-19 at a private medical college. Pakistan Journal of Medical Sciences, 36(COVID19-S4). https://doi.org/10.12669/pjms. 36.COVID19-S4.2766

8. Qureshi IA, Ilyas K, Yasmin R, Whitty M. Challenges of implementing elearning in a Pakistani university. Know Manag E-Learn. 2012;4(3) doi:10.34105/i.kmel.2012.04.025.

9. Bali S, Liu MC. Students'perceptions toward online learning and face-to-face learning courses. J Physics. 2018;1 108:012094. doi :10.1088/1742-6596/1 108/1 /012094.

10. Ali N, Jamil B, Sethi A, Ali S. Attitude of nursing students towards e- learning. Adv Health Prof Educ. 2016;2:24-29. 